\title{
On the efficiency of school tracking: a perspective from outcomes in dual VET in Switzerland
}

Joelle Latina ${ }^{1,2^{*}}$ and José V. Ramirez ${ }^{1,2}$

\begin{abstract}
In this paper, we examine the efficiency of the sort done by the Swiss lower secondary school tracking system, looking at students' outcomes in dual vocational education and training (VET) - the most common education type at the upper secondary level in the country. We discuss a simple Ricardian model about the process of school tracking based on the absolute advantage (i.e., the ability) of students in abstract learning, as opposed to contextualised learning which is more decisive in dual VET. The mismatch created by the tracking system for certain types of students is key to explain the relative track effect on outcomes in dual VET. Using administrative panel data for the Canton of Geneva, we estimate a series of zero inflated models. All results support the assumption of a miss-allocation of students to lower secondary school tracks. We thus conclude that the efficiency of the sort related to the tracking system could be improved, were students sorted on the basis of their comparative and not absolute advantage in each form of learning.
\end{abstract}

Keywords: Dual vocational education and training, Abstract learning, Contextualised learning, Tracking, Zero inflated models

JEL Classification: 20, 121, 128

\section{Introduction}

In Switzerland or in Germany, dual vocational education and training (VET) is the most common type of education at the upper secondary level (OECD 2016). Formally, dual VET programs "comprise both work-based training and formal education, in most countries at upper-secondary level, and lead to a qualification in an intermediate skill" (Wolter and Ryan 2011, 523). Admission to a dual VET program is conditioned by finding a contract with a training firm and is thus considered a marketbased mode of education. Regarding terminology, in Switzerland more than in Germany (Lassnigg 2015), the term apprenticeship is often used to denote dual VET programs. Consequently, apprentices and dual VET

\footnotetext{
*Correspondence: joelle.latina@hesge.ch

${ }^{1}$ Haute Ecole de Gestion de Genéve, HES-SO, University of Applied Sciences Western Switzerland, 17 rue de la Tambourine, 1227 Carouge, Switzerland

Full list of author information is available at the end of the article
}

students are regarded as synonymous in the remainder of this paper.

Early school tracking is a common feature of countries traditionally oriented towards dual VET, as supported by Fig. 1, which links the proportion of dual VET students and the age at first tracking in various OECD countries. The median age at first tracking in OECD countries is 15 (OECD 2012); however, Germany, Switzerland and Austria all track students from an earlier age. Denmark remains an exception among dual VET countries.

When we think about the process of tracking, i.e., how students are assigned to different tracks, in its essence, track allocation depends on school grades (OECD 2012). In Germany, teachers' recommendations play an important role as well but the latter can also be thought to heavily depend on grades. This exclusive dependence on grades is of course a simplification, as we know that, in reality, other factors also play a role (Krause and Schueller 2014; Luedemann and Schwerdt 2013; Schuetz et al. 2008). 


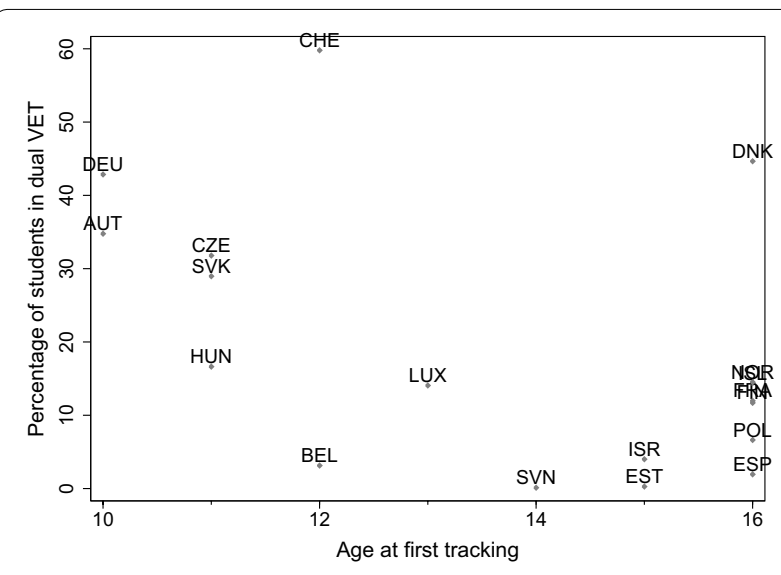

Fig. 1 Age at first tracking and the percentage of upper secondary students engaged in dual VET programs by country. Percentages of students refer to the enrollment rate of 15-19 year olds in upper secondary dual VET programs and only countries in which this proportion is greater than zero are reported in the figure. The cluster of countries in the lower right-hand side includes France, Finland, Norway and Iceland. Data source: Age at first tracking from p. 57, OECD (2012) and enrollment rates from 271, OECD (2013)

School grades traditionally reflect the ability of students to learn in an abstract form, as opposed to a situated or contextualised form of learning (Karweit 1998). The latter form is more common in vocational education and training, in which all (or at least a majority of) learning components are contextualised (Ryan 2012). Indeed, as mentioned, dual VET "combines part-time formal education with training and experience at the workplace" (Wolter and Ryan 2011, 522). In Switzerland, for example, dual VET students spend, on average, 3 days/week at the workplace (SERI 2016). Compared to academic and exclusively school-based education, the acquisition of skills in dual VET is thus dependent on different types of content and forms of assessment. The former types of education are, in contrast, structurally equivalent to lower secondary school, in the sense that requirements and assessments all heavily rely on abstract knowledge.

In a nutshell, the process of lower secondary tracking thus sorts students on the basis of their ability in abstract learning. In a two tier system, such as the one in Geneva, this ability is either above or below the required threshold, and this defines the corresponding track, high or low. In Ricardian terms, we can think about this process as a sort of students based on an absolute advantage in abstract learning: all students with an ability in abstract learning higher than or equal to the threshold are considered to have an absolute advantage.

In Switzerland, as in Germany, low track students are the natural pool of dual VET students (e.g., HupkaBrunner et al. 2010), as they are usually not admitted to academic upper secondary education. As mentioned, success in dual VET is expected to be more dependent on students' contextualised learning ability, a domain on which the lower secondary school system provides no information. The question is therefore: does a tracking system based on absolute advantage in abstract learning de facto also sorts students on the basis of their contextualised learning ability? To answer this question and organise our empirical analysis, we first discuss a simple theoretical model on the process of tracking reflecting closely what can be observed in Geneva, our case study. The main insight from the model is that the relative track effect on outcomes in dual VET depends on the effects generated by the mismatch of students to lower secondary school tracks. In terms of outcomes in dual VET, and given that the comparative advantage of students are unobservable, the efficiency of lower secondary school tracking can thus only be measured empirically. We use administrative data for 12 cohorts in the Canton of Geneva. Over a time span of 3 years after the end of compulsory education, we examine two different outcome variables related to dual VET, both measuring the accumulation of vocational human capital. We consider: the pure accumulation of years of dual training and the accumulation of years of dual training within a given occupation.

As in most Swiss Cantons, within school tracking in Geneva starts at the lower secondary level at the age of 12 and is based on primary school grades (SKBF 2014), including standardised test results in maths and in the local language, French. Lower secondary school track and grades will heavily condition the set of upper secondary choices; high track students have more options open to them than their low track counterparts. ${ }^{1}$ The only (relative) exception is admission to a dual VET program, which, in principle and as mentioned, is only conditioned on students finding a contract with a training firm. Upper secondary education revolves around three broad types: academic education in baccalaureate schools, lower level general education in specific schools and vocational education and training. ${ }^{2}$ VET programs can be either dual or entirely school-based. The difference between Geneva and other Swiss Cantons resides mainly in the proportions of students in each type of education, much more than in the structure of the system. As touched upon, the proportion of students in baccalaureate schools is the

\footnotetext{
${ }^{1}$ Note that, as in Germany (Krause and Schueller 2014), the track permeability during lower secondary school is very low in Switzerland (OECD 2012)

2 In all three types of education, students may obtain a Baccalaureate after 4 years but of different types (academic, vocational or specialized).
} 
highest in the country, while the proportion of VET students is the lowest (SKBF 2014).

Given this local setting, only a small fraction of teenagers make a direct transition to dual vocational education and training after ending compulsory education (lower secondary school). When looking at outcomes in dual VET, this creates many zeros. To accurately handle this data feature, we estimate a series of zero inflated models and find that, although lower secondary school low track students are, as expected, much more likely to engage in dual VET, they are less successful in accumulating vocational human capital than their high track counterparts. This pattern holds for both outcome variables. Additionally controlling for cognitive (grades or PISA score) and non cognitive skills (locus of control) does not affect track results. Overall, these results suggest that the efficiency of the tracking system could be improved, were students sorted on the basis of their comparative and not absolute advantage.

The remainder of this paper is structured as follows: the next section presents first a simple Ricardian model describing the process of tracking and then contains a short review of the relevant literature. The empirical framework can be found in Sect. 3: the data and variables used for the analysis are described first, then the modeling strategy is detailed. Sect. 4 presents our results and Sect. 5 concludes.

\section{The tracking system: a simple model}

The purpose of this section is to lay out a simple model to organise our analysis of the sorting process done by the lower secondary school tracking system in Geneva. Note that while this model reflects the main feature of lower secondary school tracking in Geneva, it is also intended to shed light on the general process of (early) school tracking. Given that one of the aims of school tracking is to specialize a certain type of students into academic education, we draw a parallel with a classic Ricardian trade model.

There are $N$ students in a given cohort. Assume that each student $i$ has only one factor of production, his or her effort, to produce two different types of knowledge: abstract knowledge, noted $B$, or contextualised knowledge, noted $C$. Moreover, each student has a given ability (noted $a$ ) to produce each type of knowledge; think of it as the available learning technology. Effort requirements, i.e., the amount of effort a student has to make to produce one unit of knowledge, are inversely related to the student's ability in each type: better students acquire knowledge with less effort. We thus define $e_{B}^{i}$ and $e_{C}^{i}$ as the two levels of effort for student $i$ to produce, respectively, one unit of abstract knowledge and one unit of contextualised knowledge.
The opportunity cost $(O C)$ of student $i$ to produce one additional unit of abstract knowledge represents the amount of contextualised knowledge that must be foregone. As in the Ricardian model, this opportunity cost can be expressed in terms of effort requirements:

$$
O C_{B, C}^{i}=\left(\frac{e_{B}}{e_{C}}\right)_{i} \equiv\left(\frac{a_{C}}{a_{B}}\right)_{i}
$$

where $O C_{B, C}^{i}$ denotes the opportunity cost of abstract knowledge in terms of contextualised knowledge for student $i$.

If we assume that ability in each type of knowledge is distributed over a continuum of values, there will also be a continuum of opportunity costs which can be ranked in ascending order. This ranking has two implication: first there will be students with high(er) opportunity costs and students with low(er) opportunity costs. Students who have a relatively high ability in abstract knowledge will have a lower opportunity cost. Second, the ranking will define the group of students possessing a comparative advantage in abstract knowledge (noted $C A_{B}$ ) and conversely the group with a comparative advantage in contextualised knowledge (noted $C A_{C}$ ).

If students were to choose freely which type of knowledge to produce, the Ricardian model predicts that each student would then fully specialise in the production of a certain type of knowledge, according to his or her comparative advantage. In an education setting, this implies that students with comparative advantages in abstract knowledge should follow an academic path and the others should follow a vocational path. On the basis of this argument, as soon as the school system decides to track (and thus to sort) students, it should thus consider their comparative advantage. However, that is not how lower secondary school tracking generally works, even in Geneva, where VET is an important component of the education system.

The school system only assesses the ability of students in abstract knowledge and then does a sort. This sorting process can thus be thought to be based on the absolute advantage of students. Those with an ability above a certain performance threshold are all sorted into the high track, and are considered to have an absolute advantage in abstract knowledge (noted $A A_{B}$ ).

The absolute advantage of students in contextualised knowledge is never (or very poorly) observed within the lower secondary school system. Nevertheless, students may also be ranked on the basis of their ability in $C$. We could simply assume that those with an ability above their cohort average would be the ones with the absolute advantage in contextualised knowledge (noted $A A_{C}$ ).

Combining all these elements together, we can classify students into 6 types, depending on both their absolute 
and comparative advantages. These types and their corresponding school track are presented in Table 1.

In a two tier tracking system, types (i), (ii) and (iv) would be sorted in the high track, while types (iii), (v) and (vi) would be sorted in the low track. Remember that we assume that the absolute advantage of students in abstract knowledge solely determines their track. Now, if students had been sorted according to their comparative advantage instead, track allocation would have differed for two types only: students (iii) would have been in the high track and students (iv) would have been in the low track. Thus when sorting on absolute advantage, such a tracking system misplaces two types of students.

What are the consequences of this allocation on the choice of upper secondary education, the period in which we are interested in this paper? Let us first look at the logic of the school system: high track students are generally expected to continue in an academic high school, and indeed many of them do in Geneva. ${ }^{3}$ Low track students are, on the other hand, more often expected to continue their upper secondary education in vocational education and training. Admission to an academic education is still possible but requirements are very high. ${ }^{4}$

The high track-academic low track-VET logic is adapted for all student types, except the two mismatches. Student types (iv) will probably go to VET rather than academic education, because that is where they have their comparative advantage and will most likely succeed. For them the tracking mismatch may not have negative consequences in the end. Student types (iii) on the other hand, wrongfully placed in the low track, can also end up in VET, more by default than by choice. These students will probably not do very well in VET, given that they do not have their comparative advantage in this domain.

Overall, given that student types are unobserved, an empirical model will only identify the relative track effect for all student types in that track, compared to all student types in the other track. Moreover, given that we are interested in outcomes in dual VET, the relative track effect is a priori ambiguous because it depends on the relative proportions of student types from each track engaging in dual VET. In relative terms, a positive (negative) effect of the low track would mean that the sorting done by lower secondary school tracking is efficient (inefficient). In addition, given that track allocation is mainly dependent on grades, the inclusion of grades in

\footnotetext{
${ }^{3}$ Around $70 \%$ of high track students enter an academic high school right after lower secondary education (Geneva Schooling Database, 1993-2007).

${ }^{4}$ Only less than $2 \%$ of low track student enter an academic high school right after lower secondary education (Geneva Schooling Database, 19932007).
}

Table 1 The 6 types of students and their corresponding lower secondary track

\begin{tabular}{llllll}
\hline & $\boldsymbol{C A}_{\boldsymbol{C}}$ & $\boldsymbol{C A}_{\boldsymbol{B}}$ & $\boldsymbol{A A}_{\boldsymbol{C}}$ & $\boldsymbol{A A}_{\boldsymbol{B}}$ & School track \\
\hline Students (i) & No & Yes & Yes & Yes & High \\
Students (ii) & No & Yes & No & Yes & High \\
Students (iii) & No & Yes & No & No & Low \\
Students (iv) & Yes & No & Yes & Yes & High \\
Students (v) & Yes & No & Yes & No & Low \\
Students (vi) & Yes & No & No & No & Low \\
\hline
\end{tabular}

Lower scripts $C$ and B stand for contextualised and abstract knowledge, respectively. CA stands for comparative advantage and AA for absolute advantage

an empirical model should not affect the direction of the track effects, even though their magnitudes may change.

A few studies assess the effect of tracks (and grades) on outcomes in dual VET in Switzerland, Hupka-Brunner et al. (2010) use a Swiss nationally representative panel (TRansition from Education to Employment, the so-called TREE data) and find that high achievers tend to choose exclusively school based vocational education as opposed to dual VET, a finding consistent with a sort based on abstract learning. Siegenthaler (2011) looks at the predictive power of externalised achievement tests on vocational outcomes on a subset of apprentices in the retail sector. He finds that lower secondary school track and Grade Point Average (GPA) provide more reliable information than external test results in predicting vocational outcomes. Using a subsample of TREE data, Mueller and Wolter (2014) find that among aspiring apprentices, school grades are an important predictive factor when looking at a successful entry into dual VET, and that underachievers are more likely to experience problems, such as dropping out, repeating a year or failing the external exam.

\section{Empirical framework}

\subsection{Data and variables}

We rely on the Geneva Schooling Database (GSD), an exhaustive administrative panel dataset recording all pupils in the Canton for the period 1993-2007, which in total amounts to 12 cohorts. The database is compiled and yearly updated by the school administration to increase accuracy. Outcome variables are examined for the first 3 years of upper secondary education. Because some dual VET programs may be completed in 3 years and given that we do not have information on qualifications obtained, we restrict the time span to the first 3 years of upper secondary education. We thus make sure that dropouts are not simply students who qualified and got a job. 
In addition to GSD data, for the latest 2 cohorts of students (i.e., those in the first year of upper secondary education in 2004 and 2005, respectively), we could access information on their grades obtained during their last year of lower secondary education. Moreover, a subsample of one of these two cohorts took part in the 2003PISA study. We could match their scores to our database and will, therefore, exploit this information as well. Finally, we complemented the database by matching the type of dual VET qualification pursued with three-digit ISCO codes, using the 2008 nomenclature, ${ }^{5}$ thus classifying all fields of dual VET into occupations.

In the first part of the analysis, we look at the (gross) number of years of dual VET accumulated by individuals by the end of 3 years of upper secondary education, which implies that all individuals in the data are covered. This count of years accumulated in dual VET is in close line with the strand of literature proxying human capital accumulation through years of education (e.g., Card 1999). We simply transpose this idea in the context of dual VET and try to shed some light on this accumulation process, which, as discussed, heavily relies on contextualised learning. This first outcome variable should, therefore, be thought to represent the accumulation of vocational human capital by students over a specific time span. Thanks to this first outcome, we will be able to examine whether the structural logic of the tracking system holds, i.e. if students sorted in the low track are actually better, on average, at accumulating years of dual VET. Note that accumulating years of dual VET does not represent success in upper secondary education per se, as students might end up accumulating others forms of human capital. However, and crucially, all those other types of human capital relies more heavily on abstract knowledge than dual VET.

Table 2 presents the distribution of outcome one for our sample broken down by lower secondary school track. Around a quarter of all students totalise at least a year of dual VET and, consequently, one can notice the large prevalence of zero counts in the data. As expected, around half of all low track students accumulate at least a year of training in dual VET, while only $11.4 \%$ of high track students do so.

In a second part, we refine the outcome variable to take the occupation dimension into account. Looking at the number of years of training accumulated can indeed be a too crude measure of human capital accumulation in dual VET, especially if a dual VET student switches occupations over the years; 1 year of dual training in a bank

\footnotetext{
5 This implies that for some cases (less than $2 \%$ ), no match could be found and a missing value was, therefore, imputed.
}

Table 2 Distribution of the number of dual VET years accumulated by lower secondary school track

\begin{tabular}{lrrrrrrr}
\hline \multirow{2}{*}{ No. of years } & \multicolumn{2}{l}{ High track } & & & \multicolumn{2}{l}{ Low track } & \multirow{2}{*}{ Total } \\
\cline { 2 - 3 } & $\mathbf{N}$ & \% & & N & \% & \\
\hline 0 & 22,086 & 88.6 & & 5256 & 49.8 & 27,342 \\
1 & 957 & 3.8 & & 1755 & 16.6 & 2712 \\
2 & 990 & 4.0 & & 2127 & 20.1 & 3117 \\
3 & 895 & 3.6 & & 1420 & 13.4 & 2315 \\
Total & 24,928 & 100 & & 10,558 & 100 & 35,486 \\
\hline
\end{tabular}

Data source: Geneva Schooling Database for 12 cohorts, 1993-2007

Students tracked at thirteen are excluded from the table; they represent $17 \%$ of all students

and 1 year in a bakery might not bring the same level of vocational human capital as two consecutive years in a given occupation. To overcome this limitation, we thus add the occupation dimension to the count, and combine them to form our second outcome variable. In this sense, this second outcome may give a more adequate picture of the level of specific and vocational human capital accumulated by dual VET students.

Conducting a fine-grained analysis requires a trade off between a high level of disaggregation, where no general conclusion can be reached, and a too general picture, where some information would be lost. We chose a somewhat mezzo level of disaggregation, classifying dual VET occupations at the ISCO three-digit level and simply count the number of dual VET years spent in a given ISCO occupation.

The highest modality corresponds to 3 years of dual VET accumulated in a given ISCO occupation. The second modality corresponds to students who accumulate two consecutive years of dual VET in a given occupation. The last positive modality corresponds to students who only accumulated a year of dual VET within a given ISCO occupation, regardless of the total number of years of dual VET accumulated (1,2 or 3). The dependent variable takes, therefore, four different modalities and the distribution of those outcomes broken down by track is presented in Table 3.

Note that, in a 2 year period, a dual VET student could theoretically obtain the lowest of all VET qualifications, the VET diploma (for more details, see Kammermann et al. 2011). In theory, and since we cannot control for the type of diploma pursued, defining the accumulation of vocational human capital in this way could potentially bias the effect of the track and the grade upwards, as only low achievers engage in 2-year programs and, from our perspective, those individuals would never be able to achieve the highest outcome. However, in our data only $12 \%$ of individuals who total 2 years of dual VET do so 
Table 3 Distribution of the number of dual VET years accumulated within a given three-digit ISCO occupation

\begin{tabular}{|c|c|c|c|c|c|}
\hline \multirow[t]{2}{*}{ Description } & \multicolumn{2}{|c|}{ High track } & \multicolumn{2}{|c|}{ Low track } & \multirow[t]{2}{*}{ Total } \\
\hline & $\mathbf{N}$ & $\%$ & $\mathbf{N}$ & $\%$ & \\
\hline 0 years of dual VET & 22,086 & 88.6 & 5256 & 49.8 & 27,342 \\
\hline 1 year of dual VET & 133 & 4.5 & 2334 & 22.1 & 3467 \\
\hline $\begin{array}{l}2 \text { years of dual VET within the same } \\
\text { ISCO }\end{array}$ & 916 & 3.7 & 1826 & 17.3 & 2742 \\
\hline $\begin{array}{l}3 \text { years of dual VET within the same } \\
\text { ISCO }\end{array}$ & 793 & 3.2 & 1142 & 10.8 & 1935 \\
\hline Total & 24,928 & 100 & 10,558 & 100 & 35,486 \\
\hline
\end{tabular}

Data source: Geneva Schooling Database for 12 cohorts, 1993-2007

Students tracked at 13 excluded from the table

during their first and second year of upper secondary schooling, and an additional $5 \%$ of these individuals transition to another route during their third year. Since we have no precise information on the diploma pursued and its theoretical duration, these people could simply drop out from their 3 year dual VET program. A plausible story given that, descriptively, the percentage of individuals effectively engaged in a 2-year dual VET program is low, around $4 \%$ of all VET students (Swiss Federal Statistical Office 2014). Hrizi et al. (2014) additionally show that the mean age at entry into a 2-year vocational training program in Geneva is 19 years old, and that, more importantly, practically no one starts a 2 -year qualification right after lower secondary school.

Among high track students with at least a year of dual training, around $30 \%$ of them accumulate 3 years within the same occupation, while this proportion is slightly lower among low track students (24\%). Finally, when considering only students with at least a year of dual VET, high track students accumulate more years of dual VET, on average, than their low track counterparts (the difference amounts to 0.041 year). This difference is even larger for the second outcome (here, the difference amounts to 0.105 year). However, this descriptive difference is not sufficient to test the efficiency of school tracking: it remains to be seen if it persists, once we control for additional variables, such as students' background.

As previously mentioned, we had access to lower secondary school grades of the two most recent cohorts. In our analysis, we use two different indicators: the cumulative (normalized) Grade Point Average (GPA), obtained as an average of three annual grades: French, Math and German $^{6}$, a central exam test score in math (which is external to lower secondary schools and partially standardised). For a subsample of the GSD 2002 cohort, we

\footnotetext{
${ }^{6}$ These subjects heavily condition access to all upper secondary tracks.
}

Table 4 Grade distribution by track

\begin{tabular}{|c|c|c|c|c|c|c|}
\hline & \multicolumn{3}{|c|}{ High track } & \multicolumn{3}{|c|}{ Low track } \\
\hline & Mean & Std dev. & $\mathbf{N}$ & Mean & Std. dev. & $\mathbf{N}$ \\
\hline $\mathrm{GPA}^{\mathrm{a}}$ & 0.125 & 1.04 & 4212 & -0.516 & 0.723 & 1511 \\
\hline Std math score ${ }^{a}$ & 0.167 & 1.03 & 4214 & -0.360 & 0.823 & 1490 \\
\hline $\begin{array}{l}2003 \text { PISA score } \\
\text { in math }{ }^{b}\end{array}$ & 0.011 & 0.72 & 1005 & -0.130 & 0.954 & 289 \\
\hline
\end{tabular}

Data source: Geneva Schooling Database

Pisa scores have been normalized on our sample

Grades have been normalized on the 2 cohorts sample to have zero mean and a standard deviation of 1

Students tracked at a later stage are excluded from the table

a Two cohorts, 2003-2004

b All students tested in Geneva by PISA 2003 which corresponds to our GSD 2002 cohort

accessed their 2003 PISA scores. All performance indicators are normalised over the complete grade sample.

Table 4 presents the distribution of the GPA, math test score and the available information on PISA scores, all broken down by track. The overall picture is as expected, the performance of high track students is higher, regardless of the indicator.

When considering other types of less academic subjects, such as history or geography, where perhaps, the performance of potential dual VET students could be more similar, the picture is very similar: lower overall performance and lower standard deviation around their group mean. This suggests that even less academic subjects rely heavily on abstract learning.

The list of independent variables, explanatory and control variables, is essentially the same across both parts of the empirical analysis and exploits the information contained in the GSD data. A complete list of individual characteristics taken into account is presented in Table 5 . Additional file 1: Table S1 presents some descriptive statistics for two samples: first, for the whole population and then, for the sub-population of students totaling, at least, a year in dual VET. As has been found previously in the literature (e.g. Meyer 2011), descriptives show that the population of dual VET students is indeed quite different from the complete cohort population and generally social-economically less advantaged.

\subsection{Modeling strategy}

Given that we examine two counts based on the number of years of dual VET accumulated by each student in the population, this poses two methodological challenges. First, as mentioned in the introduction, academic education is usually the first choice of high track students in Switzerland and this is even more true in Geneva. This situation de facto implies that there are many individuals 
Table 5 Description of independent variables

\begin{tabular}{|c|c|c|}
\hline & Variable name & Description \\
\hline \multirow[t]{3}{*}{ Explanatory variables } & $\begin{array}{l}\text { Lower secondary school } \\
\text { track: high, low or } \\
\text { tracked at } 13\end{array}$ & $\begin{array}{l}\text { Set of three dummy variables reflecting the (within-) lower secondary school track during the last } \\
\text { year of compulsory school: high track (reference group), low track or tracked at } 13 \text {. This latter } \\
\text { category refers to a delayed tracking system concerning } 3 \text { lower secondary schools (out of 17), } \\
\text { which, for historical reasons (Bain et al. 2004), tracked their students at the age of } 13 \text { instead of } 12 . \\
\text { They also applied a different form a tracking for the two remaining years of lower secondary school } \\
\text { curriculum. Note that this group of students is not directly comparable with either high or low } \\
\text { track students }\end{array}$ \\
\hline & Grades & $\begin{array}{l}\text { Two indicators: either the annual cumulative Grade Point Average (GPA) in the last year of lower sec- } \\
\text { ondary school obtained averaging annual grades in Maths, French and German; or the standard- } \\
\text { ised math test score result of a standardised test in math taken during the same year. Information } \\
\text { available only for the two most recent cohorts. Note that grades are partially track specific, as even } \\
\text { externalised evaluations differ in their content between high and low tracks }\end{array}$ \\
\hline & PISA score in maths & $\begin{array}{l}\text { PISA stands for Program for International Student Assessment and "is a triennial international survey } \\
\text { which aims to evaluate education systems worldwide by testing the skills and knowledge of } \\
\text { 15-year-old students" (OECD 2016). It is carried out by the OECD. PISA scores are available for a } \\
\text { subsample of the } 2002 \text { GSD cohort who took the } 2003 \text { PISA test }\end{array}$ \\
\hline \multirow[t]{9}{*}{ Controls } & Repeater & Controls for grade repetition during lower secondary school \\
\hline & Girl & Zero for boys \\
\hline & Age & Controls for potential age effects \\
\hline & Family structure & $\begin{array}{l}\text { One if the students does not live with both parents. This variable has been shown by several studies } \\
\text { to matter; e.g. Heckman (2011) }\end{array}$ \\
\hline & Non-French speaker & $\begin{array}{l}\text { One if the home language of the student is not French; see Cobb-Clark (2012) for another study } \\
\text { showing the importance of this variable }\end{array}$ \\
\hline & $\begin{array}{l}\text { Foreign country of } \\
\text { provenance }\end{array}$ & One if a student arrives in Geneva from abroad and 0 if not (i.e. from elsewhere in Switzerland) \\
\hline & Nationality groups & $\begin{array}{l}\text { Set of seven dummies grouping nationalities based on the incoming migration waves to Switzerland } \\
\text { since the 1950s (Mahnig and Piguet 2003). "Swiss" is the contrast group and the other groups are: } \\
\text { Spain and Italy; Portugal; Balkans \& Turkey; Extra European countries; R.o. EU } 27 \text { and EFTA }\end{array}$ \\
\hline & Socioeconomic status & $\begin{array}{l}\text { Carefully built by the school administration to accurately reflect the parental socioeconomic status. } \\
\text { Categories are: managerial workers; blue collars; self employed and miscellaneous/NA. The refer- } \\
\text { ence group is white-collar workers. Unfortunately, no income variable is available in the data }\end{array}$ \\
\hline & Religion groups & $\begin{array}{l}\text { Set of dummies taking into account the main religions (at the local level): Protestant, Catholic, Muslim } \\
\text { and "other". The reference group is made of Catholic students }\end{array}$ \\
\hline
\end{tabular}

with 0 years of dual VET (during the first 3 years of upper secondary education) and consequently a large prevalence of zeros in our data. Second, people getting a positive count are not a randomly selected group and the model thus needs to account for this selection effect as well.

Zero inflated models are two part models that are able to jointly address these two issues. First, as their name suggests, they account for the excess of zero counts. Second they permit to jointly model the intensive and extensive margins, in estimating simultaneously two equations, one related to participation (extensive margin) and one related to the count (intensive margin).

Compared to other fields, such as health economics (e.g., Fuemeller et al. 2013), accident modeling (e.g., Li et al. 2008) or ecological economics (e.g., Kuhnert et al. 2011), zero inflated models have been relatively sparingly used when dealing with educational outcomes. A few noteworthy examples are: Roebuck, French and Dennis (2004), who looked at the link between marijuana use, high school dropouts and truancy outcomes using as zero inflated negative binomial model; and Temple and Reynold (2007), who looked at the effectiveness of preschool participation on years of special education and on the number of arrests, using a zero inflated negative binomial model.

In this paper, we use a zero-inflated Poisson (ZIP) regression, as was first proposed by Lambert (1992) to model defaults in a manufacturing process. In this case, the first stage of the model is a simple binary logit dealing with the selection of individuals into two (latent) groups: a possibly positive outcome group and an always zero outcome group. The second part then uses a Poisson regression to model the count of years for individual belonging to the group that may have a positive outcome.

This model structure has two main implications: first, in a zero-inflated model, an individual crossing "the hurdle" may still get a null realization, contrary to hurdle models, as zero counts are generated by two distinct processes, either from the logit part (strategic 
zeros) or through the Poisson regression (incidental zeros) (Zorn 1998). Relating this modeling feature to our specific setting, strategic zeros would concern people who chose another upper secondary route, e.g., academic education, and who never intended to start a dual VET program. Incidental zeros, could refer to people who looked for a dual VET place at a later stage, typically after doing something else for the first 2 years, and could not find one, for example because of the scarcity of training places that exists in some sectors (SERI 2015).

Second, and this is a corollary of the double nature of zeros, the model accounts for overdispertion, contrary to a simple Poisson regression (Greene 1994). Formally (and omitting subscripts), the model density can be written as a mix between a degenerate distribution at zero and a Poisson distribution (Garay et al. 2011) such as:

$$
f(y)= \begin{cases}f_{1}(0)+\left\{1-f_{1}(0)\right\} f_{2}(0) & \text { if } y=0 \\ \left\{1-f_{1}(0)\right\} f_{2}(y) & \text { if } y \geq 1\end{cases}
$$

with $y$ the observed count, our outcome variable (either outcome 1 or 2 ; see Tables 2, 3), $f_{1}(\cdot)=\frac{\exp \left(\mathbf{x}^{\prime} \boldsymbol{\delta}\right)}{1+\exp \left(\mathbf{x}^{\prime} \boldsymbol{\delta}\right)}$ the logistic density and $f_{2}(\cdot)=\frac{\exp (\lambda) \lambda^{y}}{y !}$ the Poisson density, with $\lambda(\mathbf{x})=\exp \left(\mathbf{x}^{\prime} \boldsymbol{\beta}\right)$ and $\mathbf{x}$ a vector of explanatory and control variables. The corresponding conditional expectation function (CEF) is then given by 3 .

$$
E(y \mid \mathbf{x})=\left(1-f_{1}(\mathbf{x})\right) \lambda(\mathbf{x})=\frac{\exp \left(\mathbf{x}^{\prime} \boldsymbol{\beta}\right)}{1+\exp \left(\mathbf{x}^{\prime} \boldsymbol{\delta}\right)}
$$

Finally, note that we use the term "outcome" to refer either to the dependent variable or to its modalities.

\section{Results}

\subsection{Accumulating years of dual VET}

First, to assess the effect of lower secondary school track on the accumulation of vocational human capital, we estimate a series of ZIP models ${ }^{7}$ : one on the whole sample, i.e., without grades and several using the information on grades and PISA scores. Selected results of these estimations are shown in Table 6, where only our variables of interest, track and grades, are displayed.

Additional file 1: Table S2 displays the complete results for the estimation on the whole sample, including also marginal effects. The latter are to be interpreted as the overall influence of a given characteristic on the

\footnotetext{
${ }^{7}$ Specification tests (BIC and AIC criteria and the Vuong test) have been performed and all are favoring ZIP modeling over simple Poisson and negative binomial regressions. A zero inflated negative binomial model could not be fitted to our data since no convergence could be achieved. Detailed test results are available upon request.
}

expected number of years of training achieved. Given the non linear setting, we report both marginal effects at the mean (MEM) of all covariates, as well as average marginal effects (AME). For continuous variables, the standard marginal effect is reported, while for the discrete ones, the first difference is reported instead. Note that the overall low track marginal effect is positive. This positive effect can be explained by the relative large magnitude of the coefficient on the participation equation: low track students are much more likely to accumulate years of dual VET. However, a closer look at the results is worthwhile to differentiate the relative track effect on the participation in dual VET on the one hand, and on the accumulation of vocational human capital on the other.

The two part structure of the model is reflected in the results, as we present coefficients for the zero (inflate) equation (denoted "logistic part" in the table) as well as those for the Poisson equation (denoted "Poisson part"). Coefficients from the zero equation indicate the effect of a characteristic on the likelihood of being in the latent group getting a definitive zero outcome (as opposed to the other group where a positive outcome is possible). Coefficients reported for the Poisson part indicate the influence of a given covariate on the expected count of dual VET years accumulated for people belonging to the possibly positive outcome group. In addition, the two part modeling structure implies that variables changing signs across equations are not a worrying sign. In the latter case, a change of sign simply indicates that a variable has, for instance, a positive effect on the probability to belong to the always zero group, i.e., those getting no years of dual VET, and a negative effect on the expected count for the other group of students, those who may get a positive count.

Now looking more closely at results reported in Table 6 and examining first logit coefficients (reported in the "Logistic part" column), each of them indicates the effect of a given covariate on the log odds of belonging to the always zero latent group. For example, the estimated effect of -2.232 for the low track on the whole sample indicates that low track students are more likely to get a positive count of VET years, compared to the reference case of high track students. Taking the exponential of this coefficient indicates how the odds of belonging to the latent group getting a zero outcome are affected; in this case, odds are affected by a factor 0.11 . In other words, low track students are 9.3 times more likely to get a positive count. The coefficient reported for the Poisson part $(-0.075)$ informs us that being a lower secondary school low track students is associated with a decrease in the expected rate of years 
Table 6 The effect of lower secondary school track and grades on the accumulation of years of dual VET, selected results

\begin{tabular}{|c|c|c|c|c|}
\hline & \multicolumn{2}{|l|}{ Model I } & \multicolumn{2}{|l|}{ Model II } \\
\hline & $\begin{array}{l}\text { Poisson } \\
\text { part } \\
\text { (1) }\end{array}$ & $\begin{array}{l}\text { Logistic } \\
\text { part } \\
(2)\end{array}$ & $\begin{array}{l}\text { Poisson } \\
\text { part } \\
\text { (3) }\end{array}$ & $\begin{array}{l}\text { Logistic part } \\
\text { (4) }\end{array}$ \\
\hline Low track & $-0.075^{* * *}$ & $-2.232^{* * *}$ & & \\
\hline $\mathrm{N}$ & 42,463 & & & \\
\hline GPA & $0.062 * *$ & $0.959 * * *$ & $0.096^{*}$ & $0.945^{* * *}$ \\
\hline $\begin{array}{c}\text { GPA*low } \\
\text { track }\end{array}$ & & & -0.050 & $-0.236^{*}$ \\
\hline Low track & $-0.101^{*}$ & $-2.001^{* * *}$ & $-0.124^{*}$ & $-2.080^{* * *}$ \\
\hline $\mathrm{N}$ & 6889 & & & \\
\hline Math score & $0.104^{* * *}$ & $0.676^{* * *}$ & 0.081 & $0.677^{* * *}$ \\
\hline $\begin{array}{l}\text { Math } \\
\text { score*low } \\
\text { track }\end{array}$ & & & -0.002 & $-0.216^{*}$ \\
\hline Low track & -0.086 & $-1.974^{* * *}$ & -0.079 & $-2.013^{* * *}$ \\
\hline$N$ & 6869 & & & \\
\hline PISA score & $0.025^{*}$ & 0.014 & & \\
\hline Low track & -0.158 & $-2.295^{* * *}$ & & \\
\hline $\mathrm{N}$ & 1540 & & & \\
\hline
\end{tabular}

Zero inflated Poisson estimated with robust variance. All other controls are included as well. The dependent variable is the count of dual VET years accumulated

The reference case for the lower secondary school track is the high track

${ }^{*} 0.10$; ${ }^{* *} 0.05 ;{ }^{* * *} 0.01$

accumulated by a factor equals to the exponential of this coefficient $(0.93){ }^{8}$

Concerning the results related to grades, note that we add a second specification which includes an interaction term between the lower secondary school track and the relevant grade (columns 3 and 4). The reason for doing this is that grades can be partially track specific, as standards of assessment may differ between tracks. Note that since PISA scores are both externalised and standardised measures of students achievement, we do not add an interaction term with the track dummy.

First, reassuringly, results are consistent across all performance indicators. ${ }^{9}$ The overall picture suggests that higher performers achieve fewer years of dual VET and, therefore, as a corollary, more years of exclusively schoolbased education. However, provided that they do choose

\footnotetext{
8 This fine grained analysis is made possible by the two part structure of our model, as either a simple Poisson or a negative Binomial model both estimate a negative impact of the grade on the expected count, and a large positive impact of being in the low track, both results due to the comparatively large magnitude of the negative selection into dual VET. These results are available upon request.

${ }^{9}$ Unsurprisingly very similar results are also obtained when using either the history or geography GPA. Those results are available upon request.
}

dual VET, higher performers accumulate more years of training.

When looking at PISA results, signs of the estimates are all consistent. The reduced significance of coefficients can be explained by a loss of precision due to a smaller sample size, as re-estimating the model on the reduced sample without PISA scores produces very similar results (results omitted). Concerning the reduced magnitude of the logit coefficient, a possible explanation could be the unobserved nature of PISA scores by employers: Mueller and Wolter (2014) indeed found that PISA scores were not significant when looking at the probability of entering a dual VET program. However, on the accumulation process, our results suggest that the impact of PISA is similar to other performance indicators.

These results can moreover be interpreted in the light of the simple tracking model discussed in Sect. 2. Once we account for the selection effect (logit part), we find the relative effect of the high track to be positive on the accumulation process (Poisson part). Relating this result to the different types of students, we can infer the followings: first, the majority of high track students engaging in dual VET are type (iv) students, those with a comparative advantage in contextualised learning. Second, on average, low track students are less successful in accumulating years of dual VET for two possible reasons: student types (v) and (vi) accumulate fewer years on average than type (iv) students, and/or type (iii) students represent a large share of low track students engaging in dual VET. Finally, the results on grades are also consistent with our expectation: their inclusion does not modify the sign of the relative track effect.

As robustness checks, we estimate two alternative models. First, we estimate a two part Poisson logit hurdle model, in which the main difference is the assumption regarding the nature of zeros in the data. The hurdle model implies that people passing the hurdle (i.e., engaging in dual VET) always get a positive realisation, whereas the ZIP model allows for two types of zeros as discussed. In any case, the substantive conclusions regarding the impact of both the low track and the grades are also supported by the hurdle model. Second, as pointed out by Staub and Winkelmann (2013), the ZIP model is not robust to misspecification and produces inconsistent estimates if assumptions about the data generating process are in fact violated. They thus propose a Poisson quasi likelihood framework, whereby only specifying the CEF, the quantities of interest (coefficients and semi elasticities) can be robustly estimated, though at the expense of precision. Results generally hold, although the small sample size of grades data and the large inflation factor render results rather imprecise. Full results are available upon request. 

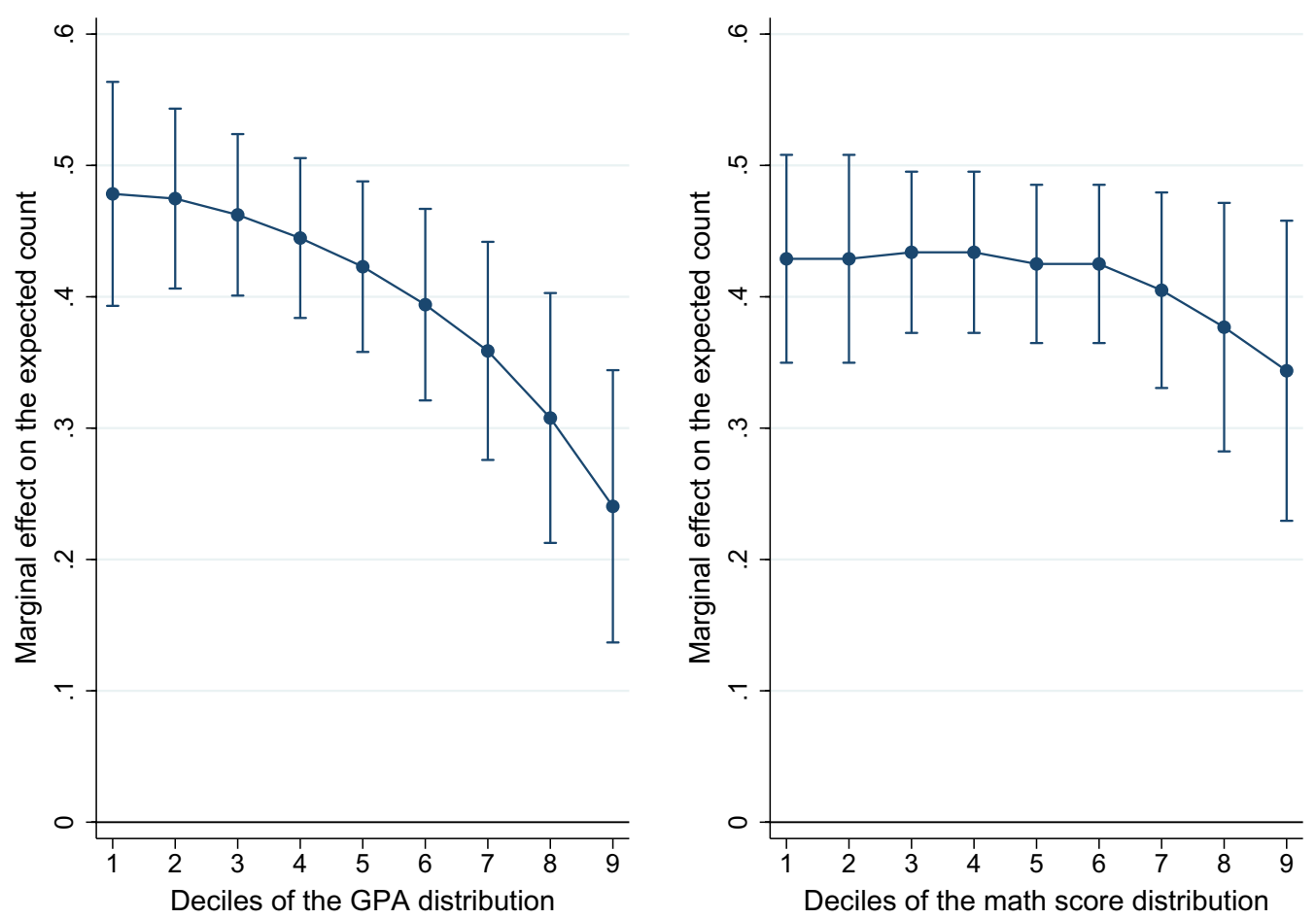

Fig. 2 Conditional low track marginal effects at different performance levels. Confidence intervals are set at the 95\% level. High track is the reference case

To deepen the analysis, we examine the evolution of low track marginal effects (on the expected count) at different values of the covariates, and especially at different performance levels. More specifically, we computed low track marginal effect at the different deciles of the grade distribution, maintaining all other covariates at their mean. This procedure was repeated for the GPA and the standardised math score. Results are shown graphically in Fig. 2, where marginal effects and 95\% confidence intervals are reported; effects have to be interpreted in contrast to the reference case, the high track. Both grades present a consistent pattern, with a low track marginal effect decreasing as one moves up the grade distribution. Said differently, this implies that low track students with high abilities in abstract learning have an expected number of years of training closer to their high track counterparts, which would correspond to type (iii) students in our tracking model. However, differences appear between the two performance indicators, with the marginal effect of the low track remaining higher when considering standardised math scores.

\subsection{Accumulating years of dual VET in a given occupation}

We now refine the definition of the outcome variable to take the occupation dimension into account. Our dependent variable, as described previously, now counts the years of training accumulated in a given ISCO three digit occupation. We repeat the estimation structure used for our first outcome variable and estimate the same set of ZIP models than before. Selected results of these estimations are shown in Table 7, where only our variables of interest, track and grades, are displayed. Additional file 1: Table S3 displays the complete results for the estimation on the whole sample.

These estimates are consistent with the ones obtained for the first outcome variable, the simple count of year accumulated in dual VET. Adding the occupational dimension does not modify the structure of the results but increases their statistical significance.

\subsection{Further results}

The goal of this subsection is to assess the robustness of our results to the inclusion of an additional control for both outcome variables. If high track students also get the best outcomes in VET, this could very well be driven by their advantageous set of non cognitive skills, which implies that omitting the latter from the model creates an omitted variable bias. For a single cohort (2003), along with grades, we possess a measure of non cognitive skills, more specifically of locus of control. Including this latter variable in the model will allow us to obtain cleaner estimates of the impact of cognitive skills, since the effect 
Table 7 The effect of lower secondary school track and grades on the accumulation of years of dual VET within a given ISCO, selected results

\begin{tabular}{lllll}
\hline & $\begin{array}{l}\text { Poisson } \\
\text { part } \\
\text { (1) }\end{array}$ & $\begin{array}{l}\text { Logistic } \\
\text { part } \\
\mathbf{( 2 )}\end{array}$ & $\begin{array}{l}\text { Poisson } \\
\text { part } \\
\text { (3) }\end{array}$ & Logistic part \\
\hline Low track & $-0.145^{* * *}$ & $-2.453^{* * *}$ & & \\
$\mathrm{~N}$ & 42,463 & & \\
GPA & $0.066^{* *}$ & $0.990^{* * *}$ & 0.100 & $0.959^{* * *}$ \\
GPA*low & & & -0.042 & -0.187 \\
track & & & $-0.194^{* * *}$ & $-2.208^{* * *}$ \\
Low track & $-0.175^{* * *}$ & $-2.161^{* * *}$ & & \\
N & 6889 & & $0.099^{*}$ & $0.697^{* * *}$ \\
Math score & $0.107^{* * *}$ & $0.704^{* * *}$ & -0.197 \\
Math & & & -0.015 & \\
score*low & & & & \\
track & & & & \\
Low track & $-0.162^{* *}$ & $-2.121^{* * *}$ & $-0.159^{* *}$ & $-2.147^{* * *}$ \\
$\mathrm{~N}$ & 6869 & & & \\
PISA score & 0.017 & 0.019 & & \\
Low track & $-0.258^{*}$ & $-2.523^{* * *}$ & & \\
N & 1540 & & & \\
\hline
\end{tabular}

Zero inflated Poisson estimated with robust variance. All other controls are included in all models. The dependent variable is the count of dual VET years accumulated

The reference case for the lower secondary school track is the high track

${ }^{*} 0.10 ;{ }^{* *} 0.05 ;{ }^{* * *} 0.01$

of non cognitive skills will now be picked up, partially at least, by the locus of control. This measure has indeed been found to be correlated with other personality traits, such as the big five (Almlund et al. 2011).

Originally developed by Rotter (1966), the locus of control captures the tendency of individuals to view life events as resulting from their own actions (internal locus) or rather from luck or fate (external locus). Internal individuals have usually more favorable outcomes, whether educational (e.g., Heineck and Anger 2010), labour market related (e.g., Piatek and Pinger 2016) or in other more general life domains such as health (CobbClark et al. 2014).

We re-estimate the same models as before for both outcome variables but now include the locus of control as an additional control. Results of those estimations are available in Additional file 1: Tables S4 and S5. No coefficient change sign, but some effects are no longer significant, most likely due to a loss of precision given the reduced sample size. ${ }^{10}$ The low track effect on the probability to accumulate years of training indicates that, at equal levels

\footnotetext{
10 This is confirmed by estimating the model on this reduced sample with and without the locus of control variable. Track effects stay in a very comparable range across both specifications, confirming that it is not the inclusion of the locus of control which renders the track dummy in the Poisson part insignificant. Results available upon request.
}

of locus of controls, low track students are much more likely to enter dual VET. Once again, these empirical results are in line with previous results.

Finally, we did two additional and related robustness checks. First, we highlight that all of our results are robust to the exclusion from the sample of individuals who could have completed a 2-year dual VET program right after lower secondary school. As discussed in Sect. 3.1, this robustness check is necessary to show that, the negative effect of the low track and the positive effect of the grade on both outcomes, do not result from an upward bias due to the pathways of 2-year dual VET students, as this latter group of students is heavily selected on the lower end of the achievement distribution. Although successful in their training program, from our point of view, these students can only (mechanically) accumulate 2 years of training and would never be able to achieve 3 years of dual VET. In both ZIP models, all parameters of interest (i.e., the low track dummy and the grade) are not much affected (results omitted). Second, we tried excluding from the sample youngsters that only accumulated 1 year of dual VET and no other form of human capital over the 3 year time span (506 individuals). The idea here is again to check for omitted variable bias: those students might have experienced personal or family related issues causing them to stop their dual VET curriculum and to drop out. As these breaks do not happen at random and their occurrence is probably correlated with our track variable, this might bias the estimated effect downwards. Excluding all of them from the sample is a conservative robustness check. We repeated the estimation presented in the first line of Table 6 on the now reduced sample. Results for the low track dummy are of a lower magnitude $(-0.032)$ and significant at 10 percent but remains negative. This result is consistent with the idea that these 506 students are very negatively selected. Therefore, we can be reasonably confident that identification is not solely driven by this group of students.

\section{Conclusion}

In this paper, we discuss the efficiency of the sort generated by the Swiss two tier lower secondary school tracking system, looking at students' outcomes in dual VET in Geneva. We examine the relative impact of the track on the accumulation of vocational human capital by dual VET students during the 3 years immediately following the end of lower secondary school. This corresponds to students aged 15-19 years. The tracking process relies on students' ability in abstract knowledge, while outcomes in dual VET are more dependent on their ability in contextualised knowledge. We present a simple $2 \times 2$ Ricardian model, classifying students on the basis of their abilities, i.e. their absolute and comparative advantages, 
in these two types of knowledge. Six types of students are identified but only two types can be thought to be missallocated by the lower secondary school system: first, students who have an absolute advantage in both contextualised and abstract learning and a comparative advantage in the former; second, students who only posses a comparative advantage in abstract learning no absolute advantage. Given that student types are unobserved, the relative track effect on outcomes in dual VET thus a priori unknown. Depending on the relative proportions of student types in each track, the estimated effect could be either positive or negative. An estimated positive (negative) sign associated with the low track dummy would imply that, on average, the sort done by lower secondary school tracking system is efficient (inefficient).

Our results show that high track students are less likely to accumulate vocational human capital. However, those who do, accumulate more vocational human capital than comparable low track students. These results hold for two different outcome variables. Once we control for three different performance indicators, including PISA scores, track effects for both outcomes remain highly significant and of the same sign. As a robustness check, we control additionally for a measure of non cognitive skills; all results hold.

Concerning the limitations of this study: first, our results can only be partially externally valid, since not all countries track students on the same basis and, more importantly, the structure of vocational education and training is different across countries. However, partial external validity does not preclude the relevance of this study: our results may be especially informative to policy makers in other Swiss cantons and in other dual VET countries, such as Germany or Austria.

A second limitation concerns the lack of information on the qualification obtained. Nevertheless, as a significant fraction of students end up with a qualification, implying a positive (but not perfect) correlation between years of education and qualification (or wages, as in the classical human capital model), we expect our results to hold when looking at the probability to qualify in dual VET.

Third, although our modeling strategy accounts for self selection, it is restricted to observables. Our results have thus to be interpreted as clean correlations between track, grades and outcomes in dual VET but not as direct causal effects.

Finally, we highlight that we only measure a relative track effect, as opposed to an absolute effect of each track. To assess the latter, one would need a counterfactual situation without any type of tracking.

If one of the goals of early tracking is to efficiently sort students, the pattern of participation into dual VET is consistent with the sort done by the lower secondary school tracking system. Low track students represent the largest pool of dual VET students. However, a finer look yields a more nuanced picture. Provided that they engage in dual VET, high track students accumulate more vocational human capital. In this sense, the sort done by the tracking system cannot be considered as efficient.

In all dual VET countries, and this is a logical consequence, upper secondary education is heterogeneous in terms of forms of learning: from purely abstract learning in academic education to (mostly) contextual learning in dual VET. Compared to countries traditionally centered on academic or general upper secondary education, such as France or the UK, forms of learning available to students at the upper secondary level are thus more diversified in dual VET countries. However, almost all dual VET countries track students from an early age, and, more importantly, sort, foremost, on the basis of students' ability in abstract learning. To improve the efficiency of this sort, the contextualised ability of students should also be assessed, which would then allow a sort of students based on their comparative advantage in each form of learning.

\section{Additional file}

Additional file 1. Additional tables.

\section{Authors' contributions}

$J L$ and JVR worked on all sections of this article. Both authors read and approved the final manuscript.

\section{Author details}

${ }^{1}$ Haute Ecole de Gestion de Genéve, HES-SO, University of Applied Sciences Western Switzerland, 17 rue de la Tambourine, 1227 Carouge, Switzerland.

${ }^{2}$ NCCR LIVES "Overcoming vulnerability: life course perspectives", Lausanne, Switzerland.

\section{Acknowledgements}

We are grateful to Michele Pellizzari, Rainer Winkelmann and Paul Ryan for useful comments and to Mark Harris and William Greene for their technical help on previous versions of this paper. Many thanks to two anonymous referees for their useful comments and suggestions. Any remaining error is ours.

\section{Competing interests}

The authors declare that they have no competing interests.

\section{Publisher's Note}

Springer Nature remains neutral with regard to jurisdictional claims in published maps and institutional affiliations.

Received: 14 April 2016 Accepted: 31 August 2017 Published online: 13 September 2017

References

Almlund, M., Duckworth, A.L., Heckman, J., Kautz, T.: Personality Psychology and Economics. In: Eric, A., SMaLW, H. (eds.) Handbook of the Economics of Education, Handbook of The Economics of Education, pp. 1-181. Elsevier, New York (2011) 
Bain, D., Hexel, D., Rastoldo, F.: Chronique d'une réforme annoncée. Les avatars d'un projet de tronc commun au Cycle d'Orientation genevois 1960-1999. Cahier de recherche numéro 10, Service de la Recherche en Education, Geneva, Switzerland (2004)

Card, D.: The causal effect of education on earnings. In: Card, D. (ed.) Handbook of Labor Economics, vol. Part A. Elsevier, New York (1999)

Cobb-Clark, D.A., Sinning, M., Stillman, S.: Migrant youths' educational achievement the role of institutions. ANN Am Acad Political Social Sci 643(1), 18-45 (2012)

Cobb-Clark, D.A., Kassenboehmer, S.C., Schurer, S.: Healthy habits: the connection between diet, exercise, and locus of control. J Econom Behav Organ 98, 1-28 (2014). doi:10.1016/j.jebo.2013.10.011

Fuemmeler, B., Lee, C.T., Ranby, K.W., Clark, T., McClernon, F.J., Yang, C., Kollins, S.H.: Individual- and community-level correlates of cigarette-smoking trajectories from age 13 to 32 in a US population-based sample. Drug Alcohol Depend 132, 1-2 (2013)

Garay, A.M., Hashimoto, E.M., Ortega, E.M., Lachos, V.H.: On estimation and influence diagnostics for zero-inflated negative binomial regression models. Comput Stat Data Analysis 55(3), 1304-1318 (2011)

Greene, W.H.: Accounting for excess zeros and sample selection in Poisson and negative binomial regression models. NYU Working paper EC-94-10:37 (1994)

Heckman, J.J.: The economics of inequality: the value of early childhood education. Am Edu 35(1), 31-35 (2011)

Heineck, G., Anger, S.: The returns to cognitive abilities and personality traits in Germany. Labour Econom 17(3), 535-546 (2010)

Hrizi, Y., Mouad, R., Petrucci, F., Rastoldo, F.: Les parcours de formation des jeunes en difficultés scolaires ià la fin du cycle d'orientation. Note d'information du SRED numéro 65, Service de la Recherche en Education, Geneva, Switzerland (2014)

Hupka-Brunner, S., Sacchi, S., Stalder, B.E.: Social origin and access to upper secondary education in Switzerland: a comparison of company-based apprenticeship and exclusively school-based programmes. Swiss J Sociol 36(1), 11-31 (2010)

Kammermann, M., Stalder, B.E., Haettich, A.: Two-year apprenticeships: a successful model of training? J Vocat Edu Train 63(3), 377-396 (2011)

Karweit, N.: Contextual learning: a review and synthesis Tech. rep. US Department of Education, Washington, D.C. (1998)

Krause, A., Schueller, S.: Evidence and persistence of education inequality in an early-tracking system: the German case. Tech. Rep. IZA DP 8545, IZA Institute for the Study of Labor, Bonn (2014)

Kuhnert, P.M., Griffiths, S., Brewer, D.: Assessing population changes in bycatch species using fishery-dependent catch rate data. Fish Res 108(1), 15-21 (2011)

Lambert, D.: Zero-inflated Poisson regression, with an application to defects in manufacturing. Technometrics 34(1), 1-14 (1992)

Lassnigg, L.: The political branding of apprenticeship into the 'Dual System': reflections about exporting the myth of employment transition. In: Heikkinen, A., Lassnigg, L. (eds.) Myths and Brands in Vocational Education, pp. 78-98. Cambridge Scholars Publishing, Newcastle upon Tyne (2015)

Li, Z., Knight, S., Cook, L.J., Hyde, L.K., Holubkov, R., Olson, L.M.: Modeling motor vehicle crashes for street racers using zero-inflated models. Accid Analysis Prev 40(2), 835-839 (2008)

Luedemann, E., Schwerdt, G.: Migration background and educational tracking. J Popul Econom 26(2), 455-481 (2013)

Mahnig, H., Piguet, E.: La politique suisse d'immigration de 1948 à 1998: évolution et effets. Les migrations et la Suisse, pp. 63-103. Seismo, Zurich (2003)
Meyer, T.: On ne prête qu'aux riches: L'inégalité des chances devant le système de formation en Suisse. Youth transitions in Switzerland: Results from the TREE panel study, vol. 1, pp. 40-65. Seismo, Zürich (2011)

Mueller, B., Wolter, S.C.: The role of hard-to-obtain information on ability for the school-to-work transition. Empir Econom 46, 1-25 (2014)

OECD: Equity and quality in education supporting disadvantaged students and schools. Organization for Economic Cooperation and Development, Paris (2012)

OECD: Education at a Glance 2013: OECD Indicators. Organization for Economic Cooperation and Development, Paris (2013)

OECD: Education at a Glance 2016: OECD Indicators. Organization for Economic Cooperation and Development, Paris (2016)

OECD: PISA 2015 Assessment and Analytical Framework. Organisation for Economic Cooperation and Development, Paris (2016)

Piatek, R., Pinger, P.: Maintaining (Locus of) control? Data combination for the identification and inference of factor structure models. J Appl Econom 31(4), 734-755 (2016). doi:10.1002/jae.2456

Roebuck, M., French, M.T., Dennis, M.L.: Adolescent marijuana use and school attendance. Econom Edu Rev 23(2), 133-141 (2004)

Rotter, J.B.: Generalized expectancies for internal versus external control of reinforcement. Psychol Monogr General Appl 80(1), 1-28 (1966)

Ryan, P.: Apprenticeship: between theory and practice, school and workplace. In: Pilz, M. (ed) The Future of Vocational Education and Training in a Changing World, pp. 402-432. VS Verlag f++r Sozialwissenschaften (2012)

Schuetz, G., Ursprung, H.W., Woessmann, L.: Education policy and equality of opportunity. Kyklos 61 (2), 279-308 (2008)

Siegenthaler, M.: Can a standardized aptitude test predict training success of apprentices? Evidence from a case study in Switzerland. Empir Res Voc Edu Train 3(2), 105-128 (2011)

SKBF: Swiss Education Report 2014 Tech. rep. Swiss Coordination Centre for Research in Education, Aarau (2014)

State Secretariat for Education, Research and Innovation (SERI): Baromètre suisse des places d'apprentissage Tech. rep. SERI, Bern (2015)

State Secretariat for Education, Research and Innovation (SERI): La formation professionnelle en Suisse: faits et chiffres 2016 Tech. rep. SERI, Bern (2016)

Staub, K.E., Winkelmann, R.: Consistent estimation of zero-inflated count models. Health Econom 22(6), 673-686 (2013)

Swiss Federal Statistical Office: Degré secondaire II: élèves selon le niveau et le type de formation, le canton, le sexe et la nationalité Tech. rep. Swiss Federal Statistical Office (SFSO), Neuchlâtel (2014)

Temple, J.A., Reynolds, A.J.: Benefits and costs of investments in preschool education: Evidence from the child-parent centers and related programs. Econom Edu Rev 26(1), 126-144 (2007)

Wolter, S.C., Ryan, P.: Apprenticeship. In: Hanushek, E.A., Machin, S., Woessmann, L. (eds.) Handbook of the Economics of Education, pp. 521-576. Elsevier, New York (2011)

Zorn, C.J.: An analytic and empirical examination of zero-inflated and hurdle Poisson specifications. Sociol Methods Res 26(3), 368-400 (1998)

\section{Submit your manuscript to a SpringerOpen ${ }^{\circ}$ journal and benefit from:}

- Convenient online submission

- Rigorous peer review

- Open access: articles freely available online

- High visibility within the field

Retaining the copyright to your article

Submit your next manuscript at springeropen.com 